employees with adapted or other work. The more prominent social importance and government demand could change the role of the occupational health physician (OHP).

The question could be asked how OHP's perceive their changing role in the re-integration process?

Methods 61 OHP's (93.8\% response) working in a Belgian occupational health service participated in a survey. Five function roles were defined:

1. 'healthcare provider': helping the employee (trust relationship);

2. 'coach': coaching and motivating the employee;

3. 'service provider': focus on employer's situation;

4. 'expert': focus on evidence based medical evaluation;

5. 'controller': employees who are able to work, obligate to do so.

The frequency of each role was asked for three different situations: occupational medical examination (OME), current attitude in re-integration examination (CARE), best possible attitude to assume in re-integration examination (BARE). Mean scores (0-10) were calculated per function role, a higher score was concordant with a higher frequency.

Results In all 3 situations the roles of healthcare (7.3-7.7) and service provider (5.8-6.2) scored similarly. The coach role was highest in the BARE (8.2), followed by the OME (7.7) and the CARE (7.0). The expert role was predominantly in the BARE (8.2) compared to the OME (6.7) and the CARE (6.6). The score for controller increased gradually from 2.9 (OME), over 3.5 (CARE) to 4.8 (BARE).

Discussion The OHP is a healthcare and service provider in all circumstances. In the BARE the most important roles were those of expert and coach, followed by healthcare and service provider. Although the role of controller had the highest score in this situation, it still remained the less important of the five roles.

\section{CHANGES IN BODY MASS INDEX BEFORE AND AFTER LONG-TERM SICK LEAVE DUE TO CANCER AMONG WORKERS: J-ECOH STUDY}

\begin{abstract}
${ }^{1,2} \mathrm{~K}$ Kuwahara* ${ }^{3} \mathrm{M}$ Endo, ${ }^{4} \mathrm{~A}$ Nanri, ${ }^{2} \mathrm{~K}$ Kashino, ${ }^{5} \mathrm{C}$ Nishiura, ${ }^{6} \mathrm{~A}$ Hori, ${ }^{5} \mathrm{C}$ Kinugawa, ${ }^{7} \mathrm{~T}$ Nakagawa, ${ }^{7} \mathrm{~T}$ Honda, ${ }^{7} \mathrm{~S}$ Yamamoto, ${ }^{8} \mathrm{~T}$ Imai, ${ }^{8} \mathrm{~A}$ Nishihara, ${ }^{9} \mathrm{~A}$ Uehara, ${ }^{10} \mathrm{M}$ Yamamoto, ${ }^{11} \mathrm{~T}$ Miyamoto, ${ }^{12} \mathrm{~N}$ Sasaki, ${ }^{12} \mathrm{~T}$ Ogasawara, ${ }^{13} \mathrm{~K}$ Tomita, ${ }^{14} \mathrm{~S}$ Nagahama, ${ }^{15} \mathrm{~T}$ Kochi, ${ }^{15} \mathrm{M}$ Eguchi, ${ }^{16} \mathrm{H}$ Okazaki, ${ }^{17} \mathrm{~T}$ Murakami, ${ }^{17} \mathrm{M}$ Shimizu, ${ }^{15} \mathrm{~K}$ Kabe, ${ }^{2} \mathrm{~T}$ Mizoue, ${ }^{16} \mathrm{~S}$ Dohi. ${ }^{1}$ Teikyo University Graduate School of Public Health, Tokyo, Japan; ${ }^{2}$ National Centre for Global Health and Medicine, Tokyo, Japan; ${ }^{3} T o k y o$ Women's Medical University, Tokyo, Japan; ${ }^{4}$ Fukuoka Women's University, Fukuoka, Japan; ${ }^{5}$ Tokyo Gas Co., Ltd., Tokyo, Japan; ${ }^{6}$ University of Tsukuba, Ibaraki, Japan; ${ }^{7}$ Hitachi, Ltd., Ibaraki, Japan; ${ }^{8}$ Azbil Corporation, Tokyo, Japan; ${ }^{9}$ Seijinkai Shizunai Hospital, Hokkaido, Japan; ${ }^{10}$ Yamaha Corporation, Shizuoka, Japan; ${ }^{11}$ Nippon Steel and Sumitomo Metal Corporation Kimitsu Works, Chiba, Japan; ${ }^{12}$ Mitsubishi Fuso Truck and Bus Corporation, Kanagawa, Japan; ${ }^{13}$ Mitsubishi Plastics, Inc., Tokyo, Japan; ${ }^{14}$ All Japan Labour Welfare Foundation, Tokyo, Japan; ${ }^{15}$ Furukawa Electric Co., Ltd., Tokyo, Japan; ${ }^{16}$ Mitsui Chemicals, Inc., Tokyo, Japan; ${ }^{17}$ Mizue Medical Clinic, Keihin Occupational Health Centre, Kanagawa, Japan
\end{abstract}

\subsection{6/oemed-2018-ICOHabstracts.1089}

Introduction To establish effective supporting system for workers returning from sick leave due to cancer is an emerging global issue. Better understanding of their physical conditions would provide important information to address this issue.
However, even simple information, for example, weight reduction by cancer type, is scarce in occupational settings. Here, we report body mass index (BMI) trajectories before and after long-term sick leave due to cancer among workers in Japan.

Methods This is a cohort study among workers in Japan who took sick leave (consecutive 30 days or more) due to cancer between April 2012 and March 2013 and returned to work until March 2014 using data from Japan Epidemiology Collaboration on Occupational Health Study. Follow-up was conducted using annual health examination data until March 2016. Longitudinal data on BMI was extracted from the annual health examination database. BMI trend change before and after sick leave and effect modification by cancer type on the change was estimated using multivariable mixed models.

Results Over 90000 workers belonged to the participating companies in 2012. One-hundred one workers newly took sick leave due to cancer in 2012. Data on BMI at least two time-points before and after sick leave each were available in 49 workers. Overall, weight reduction occurred after returning from sick leave from cancer $(p<0.001)$. The tendency of weight reduction after returning from sick leave was significantly different by cancer type $(\mathrm{p}<0.001)$. Greater weight reduction was observed in esophageal and stomach cancer $(\mathrm{n}=10)$.

Discussion We found heterogeneity in weight reduction by cancer type after returning from sick leave due to cancer. The data suggest that occupational health professionals should pay more attention in weight reduction for workers who returned from longterm sick leave due to esophageal and stomach cancer.

\section{OCCUPATIONAL RISKS IN RAILWAYS IN MOROCCO}

D Lahlou*, S Touil, B Benali, F Lhallabi, A El Kholti. Casablanca faculty of medicine and pharmacy, Hassan II university, Morocco

\subsection{6/oemed-2018-ICOHabstracts. 1090}

Introduction The sector of railways in Morocco gather numerous activities, therefore occupational risks are also numerous and varied.

Methods Our study analyses all occupational diseases and those with an occupational nature reported during 5 years from 2005 to 2009. This study is about all workers in the railway sector in Morocco. The average staff number is 8668 .

Result The number of occupational accidents reported each yearvaried between 170 and 250 cases, while the number of commuting accidents did not exceed 40 cases per year.

Discussion However, several studies showed that several risks were high in the railway sector, particularly the cardiovascular risk. The mesothelioma and asbestosis risks are also elevatedbecause of the presence of asbestos fibres in the atmosphere. And finally, these workers are also confronted to noise nuisance and psychosocialrisks.

Conclusion These occupational diseases and those with an occupational nature lay a heavy toll on human life and a significant financial burden on the industry and social security schemes. So the purpose of our work was to clarify the various hazards present in the rail transport sector in Morocco. 